\title{
PAISAJES HÍdRICOS Y POBLAMIENTO EN LA CAMPIÑa CORDOBESA A FINES DE LA EDAD MEDIA
}

\section{WATER LANDSCAPES AND POPULATION IN THE FARMLANDS OF CORDOBA AT THE END OF THE MIDDLE AGES}

\author{
JAVIER LÓPEZ RIDER \\ 152lorij@,uco.es \\ UNIVERSIDAD DE CÓRDOBA ${ }^{1}$ \\ [RECIBIDO: 19/01/2018; ACEPTADO: 12/03/2018] \\ http://dx.doi.org/10.25267/Riparia.2018.v4.05
}

\section{RESUMEN}

El objetivo del presente trabajo es dar a conocer y analizar los paisajes hídricos existentes en una parte de la Campiña del reino de Córdoba durante los siglos XIII y XV. Para ello, se empleará los datos obtenidos de la diversa documentación bajomedieval consultada, donde se muestra la profunda interacción entre la sociedad del momento y los recursos de agua existentes en todo el paisaje rural. Se detallarán las principales referencias toponímicas, construcciones hidráulicas que denotan la gestión del agua de diversos puntos geográficos y el aprovechamiento de este recurso natural tan importante en la vida de las comunidades humanas.

Palabras Claves: Humedales, Baja Edad Media, Córdoba, Paisaje rural, Historia ambiental.

\footnotetext{
1 Investigador contratado del Área de Historia Medieval de la Universidad de Córdoba, plaza del Cardenal Salazar 3, 14071 Córdoba. Contratado con cargo al proyecto de investigación HAR2015-67619P.

J. López Rider, « Paisajes hídricos y poblamiento en la Campiña Cordobesa a fines de la Edad Media », RIPARIA 4 (2018), 111-145.
} 


\section{Abstract}

The aim of this article is to present and analyze the water landscapes existing in a part of the farmlads of the kingdom of Córdoba during the $13^{\text {th }}$ and $15^{\text {th }}$ centuries. In this way, the data obtained from the diverse documents consulted in the Late Middle Ages will be used, showing the deep interaction between the society of the moment and the water resources existing throughout the rural landscape. The main toponymic references, hydraulic constructions that denote the management of the water of various geographical points and the use of this natural resource so important in the life of human communities, will be detailed.

KEY WORDS: Wetland, Late Middle Ages, Cordoba, Rural landscape, Environmental history. 


\section{Introducción ${ }^{2}$.}

De la amplia diversidad de recursos proporcionados por la naturaleza, el agua juega un papel clave para cualquier ser vivo, más aún para las sociedades históricas. La estrecha y directa relación entre las comunidades humanas y los aprovechamientos hídricos proviene desde tiempo inmemorial, suscitando que se ocasione un binomio muy representativo e indisoluble como es el de hombre/agua. Esto explica que los asentamientos de un carácter permanente elijan un lugar cercano a cualquier curso de agua, pues depende de esto para su mantenimiento y estabilidad. Como indicara Córdoba de la Llave, el desarrollo de cualquier núcleo urbano, de cualquier aldea rural, no puede entenderse sin la existencia de los recursos bídricos proporcionados por el territorio ${ }^{3}$. Una idea en la que también coincide Bonachía Hernando al plasmar que su presencia es tan indispensable para la supervivencia de los seres vivos que una de las condiciones imprescindibles para fundar una villa es que el lugar elegido para su establecimiento esté suficientemente abastecido de agua ${ }^{4}$.

En la mayoría de los tratados de agronomía conservados se alude a esta importancia del agua y su conexión con las poblaciones. Por ejemplo Ibn Jaldún aconseja:

"Pues la ciudad debe estar ubicada sobre la ribera en un río o en las proximidades de varios manantiales puros y abundantes. El

\footnotetext{
2 Abreviaturas utilizadas: AchGr $=$ Archivo de la Real Chancillería de Granada; AGA = Archivo General de Andalucía; AGS = Archivo General de Simancas; AHN = Archivo Histórico Nacional; AHPCO = Archivo Histórico Provincial de Córdoba; AHV = Archivo Histórico de Viana; AMCO = Archivo Municipal de Córdoba; $\mathrm{BCC}=$ Biblioteca de la Catedral de Córdoba; CCA = Cámara de Castilla; DIV = Diversos; PNCO = Protocolos Notariales de Córdoba; doc. $=$ documento; Ibid. =Ibidem; Núm.= número; leg.= legajo; ms. =manuscrito; s.d.= sin día; s.f. $=\sin$ folio, s.m. $=\sin$ mes.

${ }^{3}$ R. CÓRDOBa DE la Llave, "Fuentes de agua del entorno de Castro del Río a fines de la Edad Media", IV Estudios de Frontera, Tradiciones, Leyendas en la Frontera, Jaén, 2002, 171-186, 171.

4 J. A. Bonachía Hernando, "El agua en las Partidas", Mª I. Del Val Valdivieso y J. A. Bonachía Hernando (Coords.), Agua y sociedad en la Edad Media hispana, Granada, 2012, 13-64, 16-17.
} 
agua es una cosa de primera necesidad, y su cercanía ahorra muchas fatigas a los habitantes para abastecerse de ella" ${ }^{\text {. }}$.

De igual manera en las Partidas de Alfonso X el Sabio se sigue teniendo este criterio a la hora de ubicar un nuevo núcleo poblacional. En la Partida II se alude ca bien asi como es de catar el logar do quieren facer alguna buena villa, que sea sano et fuerte, et abonado de agua et de las otras cosas que fueren menester 6 . En otras ocasiones, además de considerar el agua como un bien necesario, también las zonas con abundancia tanto de ella como de vegetación son consideradas como un locus amoenus ${ }^{7}$. Todo ello hace necesario que se estudie la gestión del agua llevada a cabo por los concejos castellanos durante los siglos XIII y XV, donde manifiestan la aplicación de diversas actividades y normativas para la regulación, distribución, evacuación y consumo de tan valioso recurso ${ }^{8}$. Esto es muy evidente en el ámbito rural sobre el que existen multitud de referencias documentales y vestigios arqueológicos de una infraestructura hidráulica e industrial, que denotan el control que ejerce el poblamiento sobre los humedales ${ }^{9}$. Esta explotación refleja que el agua es un elemento único e irreemplazable, que permite determinar la relación existente entre la sociedad y el medio ambiente, al mismo tiempo que se modifica el paisaje y se articula el poblamiento ${ }^{10}$.

${ }^{5}$ I. JALDÚN, Introducción a la bistoria universal (Al-Muqaddimah), México, Fondo de Cultura Económica, 1977, 619-620.

6 J. A. Bonachía Hernando, "El agua...”, 16-17.

${ }^{7}$ R. BoDEI, Paisajes sublimes. El hombre ante la naturaleza salvaje, Madrid, 2011, 19-22.

8 Ver Ma . I. Del VAl VAldivieso, “¿Por qué estudiar hoy el problema del agua en la Edad Media?”, en L. AdÃo DA FonSECA; L. C. AmAral e Ma F. Ferreira Santos (coords.), Os reinos ibéricos na Idade Média: livro de homenagem ao Professor Doutor Humberto Carlos Baquero Moreno, Porto: FLULP, Civilização Editora, vol. 1, 2003, 1083-1089.

9 A. Orejas Saco del Valle, "La gestión del agua en época romana en el ámbito rural”, G. T. SCHATTNER y F. VALDÉS FERNÁNDEZ (Coords.), El suministro de agua a Toledo y el saber hidráulico durante la Antigüedad y la Edad Media, Berlín, 2017, 175-183, 175.

10 E. Olmos Herguedas, Agua, paisaje y ecohistoria: la comarca de Cuéllar a partir del siglo XIII, Universidad de Valladolid, 2011, 14-15 y E. MARTín GuTIÉRREZ, "El agua en Tempul a finales de la Edad Media”, L. G. LAGÓstenA BARrios (Ed.), Lacus autem ídem

«Paisajes hídricos y poblamiento en la Campiña Cordobesa a fines...» 
Conectando con esta última idea es fundamental tener presente el concepto moderno de riparia, sobre el cual se está reflexionando muchísimo en los últimos años ${ }^{11}$. A través de la aplicación de este vocablo en los estudios históricos, es posible obtener una visión interpretativa más certera de cómo las sociedades pasadas han ido gestionando las materias primas obtenidas de la naturaleza, especialmente en relación con el mundo del agua. En palabras de Ella Hermon uno de los objetivos que se pretende conseguir es d'appliquer ce concept à l'examen de la gestión intégrée de l'eau dans une large perspective pluridisciplinaire, de l'Antiquité à nos jours ${ }^{12}$. A su vez tiene un nexo de unión con la vertiente ecológica, ecohistoria o historia ambiental, centrando su principal objeto de investigación en la interacción dinámica surgida entre la sociedad y el medio ambiente, donde cobra especial protagonismo el estudio de los bords de l'eau ${ }^{13}$. De hecho, esta investigadora lo considera como une forme d'interaction directe d'une entité biotique qui est l'homme avec l'écosystème dont il fait partie ${ }^{14}$. En definitiva riparia es un concepto

et stagnus, ubi inmensa aqua convenit. Estudios históricos sobre bumedales en la Bética (II), Cádiz, 2016, 67-84, 78.

11 E. Hermon (Dir.), Ver une gestión intégrée de l'eau dans l'Empire Romain. Actes du Colloque International Université Laval, Octubre de 2006, Roma, 2008; E. Hermon (Dir.), Société et climats dans l'Empire Romain. Pour une perspective historique et systémique de la gestion des ressources en eau dans l'Empire Romain, Nápoles, 2009 y E. HERMON (Dir.), Riparia dans l'Empire Romain pour la définition du concept. Actes des Journées d'étude de Québec, 29-31 Octobre 2009, Oxford, 2010.

12 E. HeRmon (Dir.), Ver une gestión intégrée..., 9-11.

${ }^{13}$ Ma. I. Del Val Valdivieso, Agua y poder en la Castilla bajomedieval. El papel del agua en el ejercicio del poder concejil a fines de la Edad Media, Junta de Castilla y León, Valladolid, 2003, 37; E. HERMON, "Riparia dans l'Empire Romain: pour la définition d'un concept", E. HERMON (Dir.), Riparia dans l'Empire Romain pour la définition du concept. Actes des Journées d'étude de Québec, 29-31 Octobre 2009, Oxford, 2010, 3-12 y J. Dumasy, "Bilan et tendances de la recherche en paléoclimatologie et éco-histoire pour la France méridionale, VIII ${ }^{\mathrm{e}} \mathrm{XV}$ e siècle", F. CLEMENT (Dir.), Histoire et nature. Pour une histoire écologique des sociétés méditerranéennes (Antiquité et Moyen Agges), Presses Universitaires de Rennes, 2011, 127-146.

14 E. Hermon, "Espaces intégrés et définition du concept de riparia dans le monde romain", E. HERMON (Dir.), Riparia dans l'Empire Romain pour la définition du concept. Actes des Journées d'étude de Québec, 29-31 Octobre 2009, Oxford, 2010, 329-338, 333. 
muy completo que se define por su capacidad de identificar ese dinamismo ecosistémico de la acción antrópica sobre su entorno natural, poniendo especial énfasis en la gestión integral del agua ${ }^{15}$. Como indica el profesor Martín Gutiérrez, esto hace posible reflexionar sobre la ocupación de sistemas fluviales, lacustres y palustres en estrecha relación con la problemática medioambiental y las situaciones de crisis, vulnerabilidady respuestas de las sociedades del pasado ${ }^{16}$.

Considerando todo lo anterior, este trabajo se centrará en las diferentes menciones de algunos de los humedales que existían en el paisaje rural del sur del reino de Córdoba durante los siglos bajomedievales (ver figura 1). Para ello se emplearán las referencias recogidas en la documentación de la época, que ayudan a establecer una visión aproximada de los ríos, arroyos, manantiales, lagunas y demás elementos hídricos que coexistían en el marco natural de esta región. Asimismo se estudiará brevemente algunos ejemplos de ese continuo contacto entre el poblamiento asentado en la zona examinada y los cursos de agua. De nuevo se recurrirá a las fuentes archivísticas, cuya información será complementada con varios vestigios arqueológicos identificados recientemente. Con todo, se podrán conocer los recursos hídricos y algunas de las construcciones hidráulicas bajomedievales que todavía perviven en la actualidad y que conservan su denominación de origen.

Por otra parte, hay que dejar claro que no se trata de hacer un estudio de estas obras hídricas en profundidad ni de un análisis exhaustivo de las normativas y regulaciones de los

15 E. Hermon, "Préface", L. G. Lagostena Barrios (Ed.), Qui lacus aquae stagna paludes sunt... Estudios históricos sobre humedales en la Bética, Cádiz, 2015, 1-6 y E. Hermon, "L'évolution diachronique des concepts environnementaux des deux rives de l'Atlantique. La construction du concept de Riparia comme un patrimoine culturel", Riparia 1, 2015, 1-20,

${ }^{16}$ E. MARTín GutiÉRrez, "Paisajes palustres entre la desembocadura del Guadalquivir y el Guadalete durante los siglos XIII al XV”, A. MALPICA CuELlo (Ed.), Zonas húmedas de la Andalucía medieval. Inicio -de un debate, Granada, 2017, 17-49, 17.

«Paisajes hídricos y poblamiento en la Campiña Cordobesa a fines...» 
concejos de la zona y cómo las aplicaban sobre el agua para este periodo histórico, ya que respondería a la elaboración de otro estudio más amplio y con diferente finalidad. Más bien la idea es tener un primer acercamiento a la interacción de la sociedad cordobesa con su medio ambiente, haciendo hincapié a la gestión del agua y su aprovechamiento entre los siglos XIII y XV.

\section{Paisajes de agua en el entorno rural.}

Desde la conquista de la ciudad cordobesa por Fernando III el Santo en 1236 y la posterior adquisición de su Campiña entre 1240 y 1241, la instalación del contingente cristiano tanto en el marco urbano como posteriormente sobre el entorno rural del concejo de la ciudad, necesitó encargarse de regular la provisión y gestión del agua ${ }^{17}$. En ocasiones, parte de la infraestructura hidráulica ya procedía de herencia, pero mucha otra, se originó durante el periodo bajomedieval ${ }^{18}$. Si se centra la mirada sobre el término rural de la Campiña del concejo cordobés, es posible apreciar la gran diversidad paisajística que albergaba, donde los recursos hídricos cobraban especial importancia.

Hay que tener presente, que igual que ocurre en muchas ciudades castellanas, el agua no solamente procedía de un río principal, sino que también se podía obtener de capas freáticas, manantiales o cursos fluviales de pequeña y mediana magnitud ${ }^{19}$.

17 J. M. Escobar Camacho, "La Campiña de Córdoba en la Baja Edad Media: delimitación y organización espacial”, Ifigea IX, 1993, 57-75, 61-65.

$18 \mathrm{Al}$ respecto ver J. M. Escobar CAMAcho, Córdoba en la Baja Edad Media. Evolución urbana de la ciudad, Córdoba, 1989; R. Pinilla Melguizo, "Saneamiento urbano y medio ambiente en la Córdoba islámica (siglos VIII-XIII)", en J. BERBEL at alii (Eds.), Las Ordenanzas de limpieza de Córdoba (1498) y su proyección, Córdoba 1999, 39-54, y más reciente, G. Pizarro Berenguela, El abastecimiento de agua a Córdoba: arqueología e historia, Córdoba, 2014.

${ }^{19}$ R. Córdoba de la Llave, "Fuentes de agua ...”, 172 y R. IZQuierdo BEnito, "El agua en Toledo en la Edad Media", M. I. Del VAl VAldivieso y J. A. Bonachía Hernando (Coords.), Agua y sociedad en la Edad Media hispana, Granada, 2012, 211-240, 235-238. 
A través de los diversos pleitos jurisdiccionales, compra-ventas de tierras o deslindes de diversas zonas de la región analizada, se puede conocer las menciones a los diferentes paisajes de agua que existían a lo largo del territorio estudiado.

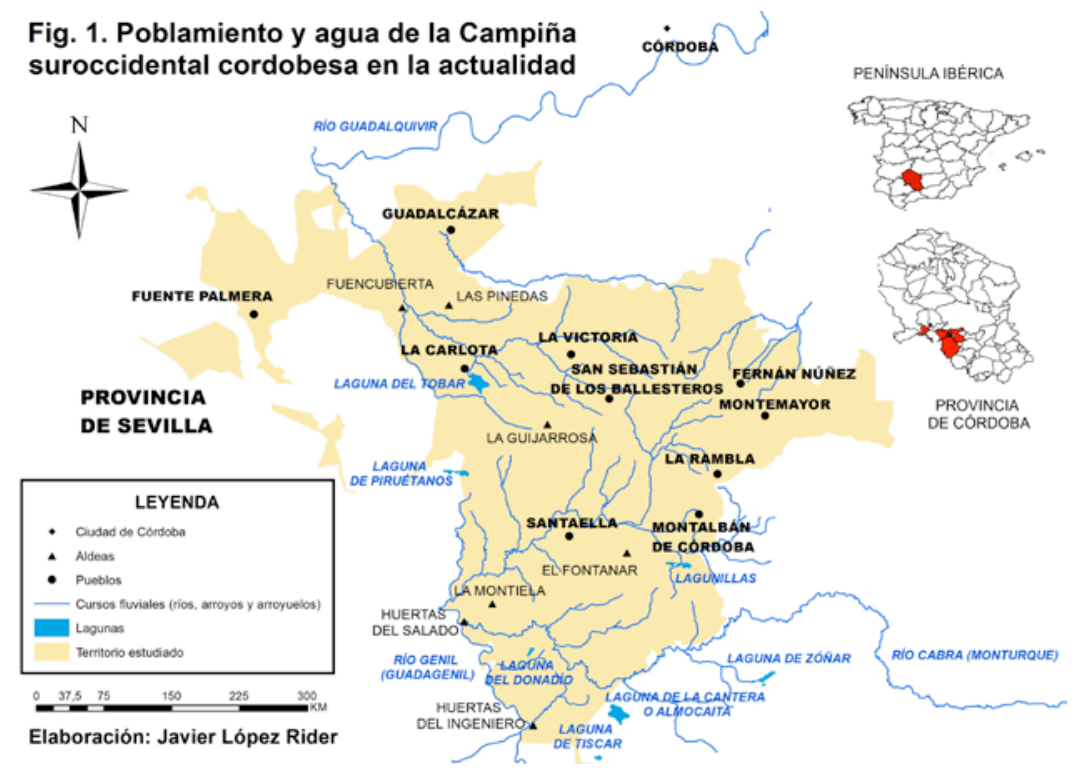

Gracias a la visita de términos del propio juez o de las declaraciones de los mismos vecinos, es posible detectar aquellos elementos hídricos que aprovechaban para diversos fines además de servir como articuladores tanto del poblamiento como del paisaje rural.

De la mayor parte de las referencias sobre hidrónimos habituales en la zona objeto de estudio, destacan una gran diversidad de cursos fluviales. Además de los tres ríos mencionados, que hoy día siguen siendo relativamente caudalosos, existe un gran número de arroyos conocidos por

«Paisajes hídricos y poblamiento en la Campiña Cordobesa a fines...» 
todos los vecinos de los núcleos de población rurales de la Campiña del reino cordobés y que se conservan actualmente. Desde finales del siglo XIII, la mayor parte de ellos eran utilizados para diferentes necesidades de la industria rural, o como el conocido Guadalquivir, para el transporte y comercio $^{20}$.

\begin{tabular}{|c|c|c|}
\hline Siglos & \multicolumn{2}{|c|}{ Cursos fluviales } \\
\hline & Ríos & Arroyos \\
\hline XIII & $\begin{array}{l}\text { Río Guadalquivir } \\
\text { Río Cabra o Monturque } \\
\text { Río Guadagenil o Genil }\end{array}$ & $\begin{array}{l}\text { Arroyo don Lucas o Torre de don } \\
\text { Lucas, Arroyo de la Fuente de la } \\
\text { Higuera, Arroyo de Gurrumiel o } \\
\text { de la Miel, Arroyo de la } \\
\text { Fuencubierta, Arroyo del } \\
\text { Arrayanal, Arroyo de Torreblanca } \\
\text { o Cañada Blanca y Arroyo de } \\
\text { Almazán o Guadalmazán }\end{array}$ \\
\hline XIV & $\begin{array}{l}\text { Río Guadalquivir } \\
\text { Río Cabra o Monturque } \\
\text { Río Guadagenil o Genil }\end{array}$ & $\begin{array}{l}\text { Arroyo don Lucas o Torre de don } \\
\text { Lucas, Arroyo de la Fuente de la } \\
\text { Higuera, Arroyo de Gurrumiel o } \\
\text { de la Miel, Arroyo de la } \\
\text { Fuencubierta, Arroyo del } \\
\text { Arrayanal, Arroyo de Torreblanca } \\
\text { o Cañada Blanca, Arroyo de } \\
\text { Almazán o Guadalmazán, Arroyo } \\
\text { del Salado, Arroyo de Abentoxil, } \\
\text { Arroyo de las Siete Torres y } \\
\text { Arroyo del Masegoso }\end{array}$ \\
\hline $\mathrm{XV}$ & $\begin{array}{l}\text { Río Guadalquivir } \\
\text { Río Cabra o Monturque } \\
\text { Río Guadagenil o Genil }\end{array}$ & $\begin{array}{l}\text { Arroyo don Lucas o Torre de don } \\
\text { Lucas, Arroyo de la Fuente de la } \\
\text { Higuera, Arroyo de Gurrumiel o } \\
\text { de la Miel, } \\
\text { Arroyo de la Fuencubierta, } \\
\text { Arroyo del Arrayanal, Arroyo de } \\
\text { Torreblanca o Cañada Blanca, } \\
\text { Arroyo de Almazán o } \\
\text { Guadalmazán, Arroyo del Salado, }\end{array}$ \\
\hline
\end{tabular}

20 R. CÓRDoba DE LA Llave, "Navegación y transporte fluvial en la Península Ibérica a fines de la Edad Media", M. CRIADO DE VAL (coord.), Actas del III Congreso Internacional de Caminería Hispánica celebrado en Morelia (México) en julio de 1996, AACHE Ediciones, Madrid, 1997, 215-233. 


\begin{tabular}{|l|l|}
\hline & $\begin{array}{l}\text { Arroyo de Abentoxil } \\
\text { Arroyo de las Siete Torres, Arroyo } \\
\text { del Masegoso, Arroyo de las } \\
\text { Higueras, Arroyo de la Saladilla, } \\
\text { Arroyo del Villar del Gallego, } \\
\text { Arroyo del Membrillar, Arroyo del } \\
\text { Gato } \\
\text { Arroyo del Colmenar, Arroyo del } \\
\text { Adelfa, Arroyo del Mármol, } \\
\text { Arroyo del Cañaveral, Arroyo del } \\
\text { Hornillo, Arroyo de las Monjas, } \\
\text { Arroyo de Caganchuelos, Arroyo } \\
\text { del Privilegio, Arroyo del } \\
\text { Garabato, Arroyo del Tarahe, } \\
\text { Arroyo de la Senda, Arroyo del } \\
\text { Lentiscoso, Arroyo del } \\
\text { Derramadero, Arroyo del } \\
\text { Pozuelo, Arroyo del Alcachofal, } \\
\text { Arroyo de Guadalcázar, Arroyo } \\
\text { de la Carcabilla, Arroyo de } \\
\text { Valdelobos, Arroyo de las } \\
\text { Peñuelas y Arroyo de Poblete }\end{array}$ \\
\hline
\end{tabular}

Tabla 1. Algunos cursos fluviales del sur del reino de Córdoba ${ }^{21}$.

21 Gran parte de los datos proceden de los siguientes documentos: 1375.08.23, AGA, Sección Priego, leg. 1107, fols. 460r-466v.; 1382.05.08, AHN, Sección Nobleza, Luque, C-754, doc. 10, fol. 2v., 1350.02.03/1493.07.05, AchGr, leg. 1432, núm. 13, fols. 1r131v., 1426.10.08, AHV, L0397, E0004, fol. 1r.; 1409.01.30, AHN, Sección Nobleza, Luque, C-796, docs. 25-26, s.f.; 1443.05.06, AGA, Sección Priego, leg. 1114, fols. 555r558v.; 1448.09.18/1531.03.17, AMCO, C-256, doc. 3, s.f.; 1448.09.11, AGA, Sección Priego, leg. 1095, fols. 208r-248v.; 1456.02.08, AHPCO, Sección clero, Lib. 6532, Tumbo del Monasterio de San Jerónimo, núm. 36, leg. 8, Memoria de la señora doña Teresa de Hoces, fols. 187r-190r.; 1465.01.29, AMCO, C-134, doc. 1., fols. 1v-10v.; 1467.05.22, AHV, C0024, E0002-2, Perg., fol. 1r.; 1471.05.18, AGA, leg. 4849, fol. 2r.; 1474.01.06/1479.08.16, AGA, Sección Priego, leg. 1107, fols. 607r-615v. y 623r-670v.; 1479.12.08, AHPCO, PNCO, 14119P, 2, fol. 1r.; 1491.03.04, AGA, Sección Priego, leg. 1030, fols. 81r-160v.; 1492.12.31, AHN, Sección Nobleza, Frías, C-1337, doc. 6, fols. 1r-2v.; 1492.01.26 a 1494.12.05, AMCO, C-1035, fols. 36r-37v. 95r.-97v., 119v-122r., 134r-136v., 174r-179r., 179r-181v., 226r-229v.,; 1492.09.25 a 1492.12.28, AMCO, C1023, doc. 79.2, s.f.; 1492.12.07, AMCO, C-258, doc. 3, s.f.; 1493.02.12, AMCO, C-256, doc. 10, fol. 135r;1493.12.08, AGA, Sección Priego, leg. 1110, fols. 236r-301v.; 1494.12.06, AHN, Sección Nobleza, Fernán Núñez, C-480, doc. 7, s.f.; 1495.06.14,/1492.02.25 AchGr, leg. 535, núm. 3, fols. 1r-330v; 1496.03.18, AMCO, C1017, doc. 30.1., s.f.; 1496.01.27, AchGr, leg. 1615, núm. 8, s.f.; 1497.11.14, AMCO, C-

«Paisajes hídricos y poblamiento en la Campiña Cordobesa a fines...» 
A grandes rasgos y como se puede apreciar en la tabla 1, la mayoría de los nombres de estos riachuelos aluden a diversas familias de plantas (Adelfas, cañaverales, lentiscos, tarajes, arrayanes, etc.), de construcciones de tipología variada (Guadalcázar, Guadalmazán o Almazán, villar del Gallego, Torreblanca, Torre don Lucas, fuente de la Higuera, Fuencubierta, pozuelo, etc.), acerca de la fisionomía del territorio (Cañada blanca, peñuelas, derramaderos, masegares, Salado, etc.) o relativo a animales (lobos o gato). Asimismo la existencia de una multitud de humedales denota la gran masa de agua que había en la zona y que justifica que proliferaran numerosos asentamientos en sus alrededores desde el periodo medieval (ver figura 1). La provincia de Córdoba cuenta con 27 humedales que han sido recogidos en el Inventario de bumedales de Andalucía. De ellos, existen varios que se ubican en la Campiña cordobesa y que son de gran importancia, como la laguna de Zóñar, la del Rincón, la de Santiago, de Tíscar, laguna Dulce, laguna Amarga, de los Jarales, de Molina Ramírez, Embalse de Cordobilla, laguna del Donadío, del Taraje, de La Quinta, del Rincón Muerto, de Cortijo Viejo, de Curado o Arco Iris, de Vadohondo o Salada, Chica o de Jarambel, de Butaquillo, de la Roa, de Casasola y Navarredonda o de Los Arenales ${ }^{22}$. Una gran parte de ellos están protegidos

277, doc. 3, fol. 3r.; 1498.05.08, AMCO, C-1717, doc. 23, s.f.; 1508.04.07, AHN, Sección Nobleza, Fernán Núñez, C-480, doc. 4, s.f.; 1512.02.13, AchGr, leg. 1573, núm. 3, s.f.; 1513.09.08, AMCO, C-171, doc. 15, s.f.; 1513.10.30 y 1513.10.23, AMCO, C-256, docs. 2 y 4, s.f.; 1514.01.12 y 1516.10.08, AMCO, C-277, docs. 14 y 4, s.f.; 1514.01.16, AMCO, C-1031, doc. 2, fol. 3r-v.; 1515.03.09, AMCO, C-1036, doc. 4, fol. 24r.; 1516.09.20, AMCO, C-242, doc. 57, s.f.; 1516.08.16 a 1516.10.01, AMCO, C-241, docs. 45 y 47, s.f.; 1519.s.m.s.d., AchGr, leg. 2468, núm. 8, s.f.; 1525.01.28, AchGr, leg. 952, núm. 1, fols. 24v-30r.; 1526.11.12-17, AMCO, C-241, doc. 41, s.f.; 1531.02.06, AMCO, C-1021, doc. 67, s.f. y 1536.03.12, AMCO, C-1039, fols. 526v-533r.

22 Ver Conserjería de Medio Ambiente, Plan Andaluz de Humedales, CMA-Junta de Andalucía, Sevilla, 2002; CONSERJERía DE MEDio Ambiente, Un día en las algunas del Sur de Córdoba, CMA-Junta de Andalucía, Sevilla, 2006; Conserjería de Medio Ambiente, Reservas y Parajes Naturales. Zonas húmedas del Sur de Córdoba. Memoria anual de actuaciones, CMA-Junta de Andalucía, Sevilla, 2007 y J. A. López-GeTA y J. Ma FornÉs AzCoITI, La geología e bidrogeología en la investigación de humedales, Junta de Andalucía, Ministerio de Ciencia e Innovación e Instituto Geológico y Minero de España, Madrid, 2009. 
adecuadamente como espacio natural, sin embargo esto no significa que dejen de encontrarse en una situación débil y de continua fragilidad ${ }^{23}$. Muchas de estas masas de agua ya existían en la Baja Edad Media puesto que se nombraban a la hora de visitar el territorio, ya sea con el mismo topónimo de hoy día o bien con el apelativo genérico de "laguna". En una sentencia del juez de términos Sancho Sánchez de Montiel, se alude a unas tierras cercanas a la torre de la Membrilla y a unas casas del cortijo de Barrionuevo, actualmente todo ello cerca del pueblo de Santaella, donde se indica:

“(...) y de ahí tomar a mano derecha a otro mojón que está en el viso hacia la laguna a ojo del pasado y de ahí adelante a otro mojón que está en un oterico, en par del asiento de las casas viejas que solían estar en lo realengo, a ojo del pasado y de ahí adelante a otro mojón que está en lo hondo de la laguna a ojo del pasado (...)" 24 .

Algunos testigos nombran la ubicación de varios piruétanos (perales silvestres) en la laguna, así lo hace Benito Sánchez, alguacil, y Antón Ruiz, pastor, que desde 1443 saben que había otro mojón que solía estar en par de unos piruétanos, que están bajo de la laguna ${ }^{25}$. En 1494 se alude a otra laguna ubicada en el entorno del villar de Ferránt Gutiérrez, posteriormente denominado Algorfillas, próximo a la villa de Fernán Núñez. Para esta ocasión se realiza un amojonamiento mencionando que (...) un poco más arriba del dicho charco y laguna en par del espino que está junto con el otro mojón pasado en lo alto ${ }^{26}$. En el actual término municipal de

23 J. Naranjo Ramírez, R. Garzón García y A. Mulero Mendigorri, "Los humedales del sur de Córdoba: conflictos y fricciones entre espacios protegidos y medio rural circundante", R. Baena Escudero et alii (coord.), Investigando en rural, Ulzama, Navarra, 2012, 493-502.

24 1492.10.01, AMCO, C-1035, fols. 92v-95r. y 1493.02.11, AMCO, C-1035, fols. 133r$134 \mathrm{r}$.

25 1493.04.s.d., AMCO, C-256, doc. 8, s.f.

26 1494.04.18, AMCO, C-1023, doc. 79.2, s.f.; 1494.03.03, AHN, Sección Nobleza, Fernán Núñez, C-483, doc. 2-nº 6, fols. 1r-3r.; 1494.03.03, AMCO, C-1035, fols. 172r-

«Paisajes hídricos y poblamiento en la Campiña Cordobesa a fines...» 
Santaella se cita una laguna que todavía hoy día se crea en los momentos de abundantes lluvias. A la hora de la delimitación de los términos entre varias villas, se construyen unos hitos divisores, donde se especifica que una linde va con el dicho camino abajando hacia la laguna ${ }^{27}$ y para el siglo XVI, todavía se mantiene la misma, señalándose (...) otro en la laguna de la Cantera ${ }^{28}$. También en la zona del actual municipio de Montemayor, se nombra otra laguna por numerosos vecinos de la región. Por citar uno de ellos, Antón Ruiz Escobar, vecino de la villa de La Rambla, declara que en el día de todos los Santos que pasó deste año de 1524, este testigo venía por una senda real que va por la laguna que dicen de Montemayor, a ora de misas mayores ${ }^{29}$.

Por otra parte, las personas que continuamente se desplazan por todo el territorio campiñés, también señalan diversos hidrónimos. Por ejemplo, algunos puntos de agua sirven para designar a cortijos y centros poblacionales, como El Padul o El Fontanar u Hontanar ${ }^{30}$. Ambos hacen alusión evidentemente a manantiales, lagunas o pantano de agua ${ }^{31}$ y están muy presentes en la zona objeto de estudio ${ }^{32}$. Del mismo modo, es común encontrarse con la terminología hondón, hondonal y hondonera, referido a zonas encharcadas o de presencia continua de agua ${ }^{33}$. Así por ejemplo al sur de la villa de Santaella se documenta el

173r.; 1494.04.18, AMCO, C-1035, fols. 179r-181v. y 1494.04.28, AMCO, C-1036, doc. 17 s.f.

27 1494.03.18, AMCO, C-1035, fols. 174r-179r.

28 1547.03.26, AMCO, C-1021, doc. 64, fol. 4v.

29 1525.01.28, AchGr, leg. 952, núm. 1, s.f.

30 R. CÓRDOBA DE LA Llave, "Fuentes de agua...”, 175.

31 A. Malpica Cuello, Las últimas tierras de al-Ándalus: paisaje y poblamiento del reino nazari de Granada, Consorcio para la Conmemoración del Primer Milenio de la Fundación del Reino de Granada, Granada, 2014, 433; G. Traina, Paludi e bonifiche del mondo antico, L'Erma di L'Erma di bretschneider, Roma, 1988, 62-65 y F. GONZÁLEZ BERNÁLDEZ, Los paisajes del agua, 84-157.

32 1475.05.18, AHN, Sección Nobleza, Luque, C-796, doc. 1-3, fols. 1r-6v.; 1547.s.m.s.d., AMCO, C-1031, doc. 1, s.f. y 1551.04.28, AchGr, leg. 725, núm. 6, s.f.

33 F. GonZÁLEZ BERnÁLDEZ, Los paisajes del agua, 103-104. 
molino del Hondón desde el siglo XVI, ubicado cerca de la ribera derecha del río Monturque (actual Cabra) ${ }^{34}$. Hay otros vocablos que se han recogido en todo el paisaje rural de la Campiña cordobesa, como el lapachar (terreno pantanoso) documentado en 1514 mostrándose el camino de Francisco hasta los rastrojos y rodea los rastrojos y da en el lapachar ${ }^{35}$. De igual forma es muy común la palabra soto o sotos, que referencia la existencia de diferentes árboles, arbustos y maleza en riberas de cursos fluviales o valles ${ }^{36}$. De hecho, entre los términos de Santaella y Écija existía desde el siglo XIII la iglesia parroquial y núcleo de población rural denominado Soto o Sotos de Santaella, cuyo hidrónimo se conserva actualmente y se encuentra en una de las márgenes del río Genil ${ }^{37}$. De igual modo, salobral (vinculados a saladares alcalinos), tarajes o tarajales (presentes en aguas mineralizadas y salinas $^{38}$, derramaderos (desagüe de las aguas de las lluvias) o vados y vaderas, están presentes en todo el ámbito rural cordobés. Como muestra basta con ojear las descripciones que se plasman en las fuentes documentales de aquellos momentos. En 1514 se nombra el camino del salobral, el camino que va a la Salina o el padrón de la Mesa hasta la ladera y asomante al salobral $l^{39}$ y cuando van a la dehesa de la Mesa se cita e atraviesa la tierra derecha al arroyo de los Salobrales ${ }^{40}$. Los tarajes son mencionados en varios arroyos que llevan el mismo topónimo como identificador, siendo el más

\footnotetext{
${ }^{34}$ J. LÓPEZ Rider, Estudio sobre construcciones hidráulicas e industriales de Santaella (Córdoba), Diputación Provincial de Córdoba, Córdoba, 2013, 95-101.

35 1514.01.16, AMCO, C-1031, doc. 2, fols. 13v-14r.

36 J. Pascual Barea, "El paisaje histórico de los términos de Tarifa y Algeciras según la toponimia del Libro de la Montería en el siglo XIV”, en E. MARTín GUTIÉRREZ, El paisaje rural en Andalucia Occidental durante los siglos bajomedievales: actas de las I Jornadas Internacionales sobre paisajes rurales en época medieval, Cádiz, abril de 2009, Universidad de Cádiz, 2011, 107-146, 129.

${ }^{37}$ BCC, ms. 125, fols. 66r-67r. y M. NiETo Cumplido, Corpus Mediaevale Cordubense, II, Montes de Piedad y Caja de Ahorros, Córdoba, 1979, n. 688, 141-142.

${ }^{38}$ F. GONZÁLEZ BERNÁLDEZ, Los paisajes del agua, 186-187 y 203.

39 1514.01.16, AMCO, C-1031, doc. 2, fols. 2r., 6r. y 7v.

40 1514.01.31, AMCO, C-1031, doc. 3, fol. 3r.
}

«Paisajes hídricos y poblamiento en la Campiña Cordobesa a fines...» 
destacado el arroyo del tarahe próximo al castillo de Montalbán ${ }^{41}$. Cerca de la villa rambleña, se nombra continuamente desde mediados del siglo XV la vereda que va desde el derramadero a las tierras de Poblete ${ }^{42}$. En cuanto a vados y vaderas son cuantiosos los casos que se han detectado, acentuándose los vados de los ríos Monturque y Genil indicados en la época como vado del concejo del Guadagenil y vado del concejo del río Monturque ${ }^{43}$. En ocasiones la mención a "ojo" de agua designa normalmente a ciertos manantiales. Para el caso que ocupa este trabajo, solamente aparece la denominada Fuente de los Ojos vinculada al poblado islámico de Almequín, que posteriormente ya en manos cristianas, pasará a llamarse Los Caños de Almeclín o Moclín, manteniendo su nomenclatura conectada al aprovechamiento hídrico ${ }^{44}$. Igualmente la palabra "nava" puede tratarse de un terreno húmedo correspondiente a una masa de agua determinada ${ }^{45}$. Como sucede con los vados o vaderas, hay un sinfín de navas utilizadas para beber y pastar con el ganado en toda la comarca rural $^{46}$.

\section{Control, gestión y usos del agua.}

Es muy evidente que la sociedad bajomedieval ha necesitado de todos los recursos disponibles en su medio natural tanto para su propio sustento como para las actividades económicas y cotidianas que desempeñaban. Esto ha producido una transformación paisajística importante a través de la ocupación y explotación de diferentes áreas de cualquier espacio rural, desembocando en una profunda interacción entre el

\footnotetext{
41 1492.s.m.s.d., AMCO, C-1031, doc. 5, fol. 2v.

42 1496.03.17, AMCO, C-257, doc. 3, s.f.

${ }^{43}$ Ibid., fols. $2 \mathrm{v}-4 \mathrm{r}$.

44 1494.12.06, AHN, Sección Nobleza, Fernán Núñez, C-480, doc. 7, s.f. y 1508.04.07, AHN, Sección Nobleza, Fernán Núñez, C-480, doc. 4, s.f.

45 F. GONZÁlEZ BERNÁldEZ, Los paisajes del agua, 15-21 y 149-154.

46 1496.04.13, AchGr, leg. 1615, núm. 8, s.f. y 1492.12.05, AMCO, C-1035, fols. 119v$122 \mathrm{r}$.
} 
hombre medieval y la naturaleza ${ }^{47}$. Una idea que matiza muy bien Bertrand al explicar que no sólo depende de las poblaciones campesinas la creación de un espacio rural, sino también de unas condiciones naturales determinadas, convirtiéndose todo en una realidad ecológica ${ }^{48}$. Por lo cual se trata de un conjunto en el que los elementos naturales se combinan dialécticamente con los elementos bumanos ${ }^{49}$. Teniendo presente estos fundamentos, está claro que de los recursos naturales susceptibles de ser explotados, el componente hídrico juega un papel principal. Las zonas húmedas localizadas han permitido la creación de diferentes núcleos de población de carácter rural, convirtiéndose esos puntos de agua en hitos que promocionan la organización y gestión del paisaje rural. Como expresó Marrocchi para el río Chiana cercare di seguire la storia dell'impaludamento della Chiana un peoca medieval significa, appunto, riconoscervi i fattori idrogeologici intrecciati con quelli antropici ${ }^{50}$.

En toda Europa se puede apreciar la fuerte presión sobre estos paisajes de agua donde las actividades, mayormente

47 M. PARra Villaescusa, “Aguas peligrosas"- aguas aprovechables: concepción ideológica y realidad productiva de los marjales. El sur del reino de Valencia (XIVXV)", Ma. I. Del VAl Valdivieso (Coord.), La percepción del agua en la Edad Media, Universitat d'Alcalat, 2015, 39-84, 39.

48 G. Bertrand, "Para una historia ecológica de la Francia rural. Primera parte: el imposible tablean geográfico", C. Bertrand y G. Bertrand, Geografía del Medio Ambiente: El Sistema GTP: Geosistema, territorio, paisaje, Granada, 2006, 161-185, 164 y J. A. GARCía dE CorTÁzAR, "Sociedad rural y entorno físico: las modificaciones del paisaje en la Castilla medieval”, E. MARTín GuTIÉRREZ (Coord.) La organización del paisaje rural durante la Baja Edad Media. El ejemplo de Jerez de la Frontera, Universidad de Sevilla y Universidad de Cádiz, 2004, 251-274, 253 y J. A. GARCía de CorTÁzAr, "Sociedad rural y medio físico en la España Medieval: Transformaciones del entorno físico en el Reino de Castilla en los siglos VIII al XV", E. PÉrEZ-EMBID WAMBA (coord.), La Andalucia medieval. Actas de las I Jornadas de Historia Rural y Medio Ambiente, 2002, 15-42, 26-27.

49 G. BERTRAnD, "Para una historia ecológica...", 165-179.

50 M. Marrocchi, "L'impaludamento della val di Chiana in epoc medievale", A. Malvolti y G. PINTO (a cura di), Incolti, fiumi e paludi. Utilizzazione delle risorse naturali nella Toscana medievale e moderna, Leo S. Olschki Editore, Firenze, 2003, 73-93, 79.

«Paisajes hídricos y poblamiento en la Campiña Cordobesa a fines...» 
económicas, eran muy diversas ${ }^{51}$. El amplio repertorio de acciones antrópicas ha provocado modificaciones sustanciales sobre el paisaje, originando un impacto importante a tener en cuenta. En una de sus reflexiones, Delort indica, por ejemplo, que quand les pluies sont revenues, la déforestation a interdit la progressive rétention des eaux. ${ }^{52}$ Incluso más adelante manifiesta que es difícil detectar qué actividades ejercidas por el ser humano influyen en el incremento de la temperatura, aunque es evidente que muchas de ellas emiten metano, dióxido de carbono u óxido de nitrógeno ${ }^{53}$.

51 Ma. I. Del Val Valdivieso, Agua y poder..., 18-20 y 152-153; M. Parra VILLAESCUSA, "Aguas peligrosas"- aguas aprovechables...", 57-61; E. MARTín GutiérReZ, La identidad de Jerez de la Frontera. Territorio y Poblamiento durante la Baja Edad Media, Universidad de Cádiz, Cádiz, 2003, 24-30; E. Olmos Herguedas, Agua, paisaje y ecobistoria..., 142-156 y K. BERTHIER, "Cîteaux y el control del agua en la Edad Media: la creación del canal de cent-fonts", 51-78, 60-64; J. TORRÓ, "Colonización cristina y roturación de áreas palustres en el reino de Valencia. Los marjales de la villa de Morvedre (ca. 1260-1330)", 147-186, 180-182 o J.-L., ABBÉ, “Técnicas de drenaje y sociedad feudal: las lagunas del Languedoc, 187-206, 190, estos tres últimos trabajos se encuentra en J. TORRÓ y G. ENRIC (eds.), Hidráulica agraria y sociedad feudal. Prácticas, técnicas, espacios, Universitat de Valencia, 2012; M. MARrocCHI, "La historiografía italiana y los paisajes rurales en Toscana en la Baja Edad Media”, en E. MARTín GuTIÉRrez, (coord.), El paisaje rural en Andalucia Occidental durante los siglos bajomedievales. Actas de las I Jornadas Internacionales sobre Paisajes rurales en época medieval, Cádiz, 1-2 de abril de 2009, Universidad de Cádiz, 2011, 157-172, 166-167; D. Balestracci, "L’uso delle acque interne nel Senese nel Medioevo", A. MAlvolti y G. PINTO (a cura di), Incolti, fiumi e paludi. Utilizzazione delle risorse naturali nella Toscana medievale e moderna, Leo S. Olschki Editore, Firenze, 2003,117-141, 118-120 y ss.; G. PINTO, "Incolti, fiui, paludi. Alcune considerazioni sulle risorse naturali nella Toscana medieale e Moderna", A. MALVOLTI y G. PINTO (a cura di), Incolti, fiumi e paludi. Utilizzazione delle risorse naturali nella Toscana medievale e moderna, Leo S. Olschki Editore, Firenze, 2003, 1-16, 12 y G. TraINA, Paludi e bonifiche..., 16.

52 R. DELORT, "Les facteurs éco-biologiques de l'espace: permanences et mutations", Uomo e spario nell'alto Medioevo. Settimane di Studio del Centro Italiano di Studi sull'alto Medioevo. 4-8 aprile 2002, Centro Italiano di Studi sull'alto Medioevo, Sopleto, 2 vols., 2003, vol. 1, 69-90, 74-75.

${ }^{53}$ Ibid., 76. La hausse générale de la température est vérifiée et admise mais on ne sait guère la préciser, ni même en repérer les causes ou les influences, parfois prépondérantes, du milieu local. La pollution par les activités humaines semble bien faible, même si les rizières ou un élevage, qui remplace peu à peu les troupeaux sauvages, contribuent à produire du méthane et si les défrichements sur brûlis ou l'attaque des forêts, influent sur les dégagements de gaz carbonique ou d'oxydes d'azote. 
Por tanto, parece clara la idea de que la sociedad medieval no dudó en llevar a cabo una gestión integral de los recursos naturales, que si se traslada al mundo del agua, se identifica fácilmente porque:

"la colonizzazione imponeva il controllo dei corsi d'acqua e questo spingeva a trasformare ulteriormente il paesaggio naturale, per rafforzare l'assetto idrico creato o modificato dall'uomo, a correggere ilcorso dei fiumi, a serrarli entro argini potenti, a impiantare e conservare una rete idrica, sempre più artificiale, coerente" ${ }^{, 54}$.

Recordando los humedales citados en líneas anteriores, se comprende que el aprovechamiento hídrico puede ser bien abordado en el caso de Córdoba. Es indudable que los diversos vestigios de construcciones hidráulicas (acueductos, aceñas, aljibes, baños, etc...) son el testimonio de que Qurtuba sobresalió como ciudad modélica en el uso racional del agua en sus distintas posibilidades relativas a la captación, transporte, acumulación, distribución y evacuación de los recursos hídricos ${ }^{55}$. En el ámbito rural analizado, existen datos fidedignos de la incidencia del poblamiento sobre las diversas masas de agua. Según un estudio realizado en la laguna de Zóñar, ubicada en el sur de Córdoba (ver figura 1), se ha detectado para la etapa medieval, un periodo cálido:

"con una pérdida total de laminación, el aumento de minerales detríticos y el aumento relativo de la susceptibilidad magnética, que indican un aumento de la erosión en la cuenca de drenaje al lago. La presencia de una facies rica en yeso y aragonito marca un aumento de la salinidad del agua del lago, causada por un descenso del nivel del lago" ${ }^{\text {"56. }}$.

\footnotetext{
54 V. Fumagalli, Paesaggi della paura. Vita e natura nel Medioevo, Bologna, Il Mulino, 1994, 217.

55 R. Pinilla Melguizo, "Saneamiento urbano y medio ambiente...”, 40.

56 C. MARTín-Puertas et alii, "La paleolimnología en la gestión de los humedales: la laguna de Zóñar”, J. A. LÓPEZ-GETA y J. Mª FORNÉs AZCOITI, La geología e hidrogeología
}

«Paisajes hídricos y poblamiento en la Campiña Cordobesa a fines...» 
También los cursos fluviales y arroyos señalados, han sufrido un proceso de explotación bastante palpable a través de las fuentes escritas y algún que otro vestigio. Sin ir más lejos, el mismo río Guadalquivir manifiesta una gran presencia de construcciones hidráulicas como aceñas, batanes, barcas o pesquerías, sin olvidar su utilización como medio de transporte ${ }^{57}$. En este sentido, el comercio de la madera a través de este río fue trascendental desde las sierras de Segura y Cazorla a las ciudades de Córdoba y Sevilla ${ }^{58}$. Por ejemplo, para el transporte de pinos se contrataban de diez a veinte operarios para que los condujeran por el río con ayuda de perchas ${ }^{59}$. Los denominados "barqueros de Córdoba" eran los encargados de llevar las mercancías entre Sevilla y Córdoba desde el siglo XIII. Solían ser unos cuarenta transportistas para el siglo XV y acudían a pernoctar en el mesón "de los Barqueros" de la misma ciudad cordobesa ${ }^{60}$.

En ríos de menores dimensiones y arroyos, también ejecutaron un fuerte control de sus aguas con fines industriales.

en la investigación de humedales, Junta de Andalucía, Ministerio de Ciencia e Innovación e Instituto Geológico y Minero de España, Madrid, 2009, 199-214, 207-211 y C. MARTíNPuertas, "Arid and Humid phases in Southern Spain During the Last 4000 Years: the Zoñar Lake Record, Córdoba”, The Holocene, 18-6, 2008, 907-921.

57 R. CÓRDOBA DE LA LLAVE et alii, Los molinos hidráulicos del Guadalquivir en la ciudad de Córdoba: estudio bistórico y arquitectónico, Centro de Estudios Históricos de Obras Públicas y Urbanismo, Madrid, 2008; R. CÓRDOBA DE LA LLAVE, "Los batanes hidráulicos de la cuenca del Guadalquivir a fines de la Edad Media. Explotación y equipamiento técnico", Anuario de Estudios Medievales 41-2, 2011, 593-622 o P. ÍÑIGO HernándeZ, "La pesca fluvial y el consumo de pescado en Córdoba (1450-1525)", Anuario de Estudios Medievales 27-2, 1997, 1045-1116.

$58 \mathrm{M}^{\mathrm{a}}$ A. CARmona Ruiz, "El aprovechamiento de los espacios incultos en la Andalucía Medieval: el caso de la Sierra Norte de Sevilla”, en E. MARTín GuTIÉRREZ, (coord.), El paisaje rural en Andalucia Occidental durante los siglos bajomedievales. Actas de las I Jornadas Internacionales sobre Paisajes rurales en época medieval, Cádiz, 1-2 de abril de 2009, Universidad de Cádiz, 2011, 193-208, 194-195.

${ }^{59}$ R. CÓRDOBA DE LA Llave, “Navegación y transporte fluvial...”, 215-233.

${ }^{60} \mathrm{~J}$. LÓPEZ RiDER, "La producción de carbón en el reino de Córdoba a fines de la Edad Media: un ejemplo de aprovechamiento del monte mediterráneo", Anuario de Estudios Medievales, 46-2, 2016, 819-858, 843-844 y R. CÓRDOBA DE LA LLAVE, "Navegación y transporte fluvial...”, 220. 
Para el Genil se documenta desde 1465 la venta de una isla situada en término de Santaella, con su puerto, azuda y estacada en el río Guadaxenil, que otorgaron Juan Ruiz Moyano y su mujer, en favor de don Alfonso de Aguilar por $8500 \mathrm{mrs}$. de precio ${ }^{61}$. Y para el río Monturque o Cabra, los ingenios industriales están bien detectados desde al menos el siglo XIV, como es el caso del molino de la Rubia y de la torre del Maestre que aparecen en la cédula de Enrique III cuando los cede a don Gómez Suárez de Figueroa, indicándose una casa y parada de molinos de pan moler y torre, que es en el río Monturque, término de Santaella, castillo de la muy noble ciudad de Córdoba ${ }^{62}$. Otros molinos harineros surgen en la documentación del siglo XV, como el de Don Martín (ilustración 1), de Don Francisco y de Fernando de las Infantas ${ }^{63}$.

61 1465.04. s.d., AGS, CCA, DIV, 41, 18.

62 1377.06.08/1375.11.21, AHN, Sección Nobleza, OSUNA, C-2978, doc. 6, s.f.; 1342.02.01, AHV, L-397, E0004, s.f. y 1426.12.06, AHV, L-387, E-0005, s.f. J. LÓPEZ RIDER, Estudio sobre construcciones hidráulicas...,104-108 y 124-133.

63 J. LÓpez Rider, "Los molinos del río Monturque en el término municipal de Santaella (Córdoba): molino de Don Martín, un legado histórico y tecnológico", Actas del $8^{\circ}$ Congreso Internacional de Molinología: Innovación y ciencia en el Patrimonio Etnográfico, Diputación de Pontevedra, Tuy, 2012, 145-156; 1495.05.13, AHPCO, PNCO, 14134P, 17, fol. 40v.; J. LÓPEZ RIDER, Estudio sobre construcciones bidráulicas..., pp. 150-166; 1498.05.08, AMCO, C-1717, doc. 23, s.f.; 1499.09.24, AGA, Sección Priego, leg. 1010, fols. 343r-348v.; 1515.s.m.s.d, AHPCO, PNCO, 11826P, fol. 389r. y para el de Fernando de las Infantas, J. LÓPEZ RIDER, Estudio sobre construcciones bidráulicas...,86-90; 1493.04.s.d, AMCO, C-256, doc. 8; 1493.02.11, AMCO, C-256, doc. 10, s.f.; 1505.10.23, AHPCO, PNCO, 14143P, 5, fol. 13r.

«Paisajes hídricos y poblamiento en la Campiña Cordobesa a fines...» 
RIPARIA VOL. 4 (2018)
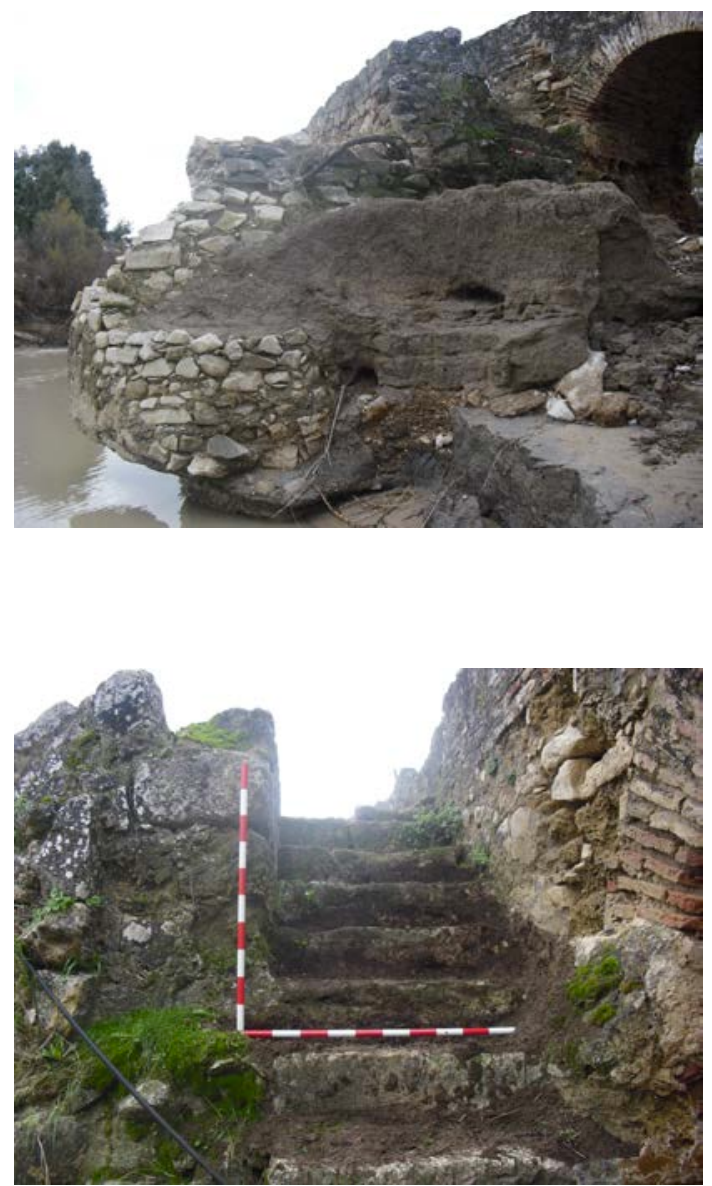

Ilustración 1. Vestigios del molino de don Martín ${ }^{64}$.

Los alfares, dedicados a la fabricación de materiales de construcción (tejas y ladrillos) y de cerámica, estaban ubicados en las inmediaciones de las villas rurales del reino de Córdoba y se abastecían de arroyos. En toda la Campiña se manifiestan abundantes ejemplos de estas instalaciones, que han sido documentadas en lugares como Castro del Río, Aguilar de la

${ }^{64}$ J. LÓPEZ RIDER, Estudio sobre construcciones hidráulicas..., p. 145 
Frontera, Baena y Montilla ${ }^{65}$. En la villa de La Rambla, desde finales del siglo XIV los vecinos de la población son barreros, cantareros, tejeros, olleros o tinajeros. Procuraban tener disponible la cantidad de agua suficiente para la obtención de barro y funcionamiento de tejares. Así por ejemplo, Catalina Fernández tenía un tejar que:

"llegaba hasta un arroyo y pasa el agua por orilla de las tapias y haciendo pozas se recoge el agua y vende el agua a los vecinos de La Ranbla cuando estos quieren usarla. [Otros aseguran que han observado] cómo sacaban barro de las hazas que están en la madre vieja hasta el olivar [...] sacaban barro los tejeros de las dichas hazas públicamente y gozaban del agua" ${ }^{66}$.

Otra actividad que se practicaba con frecuencia en los arroyos y arroyuelos era el curtido del lino, así se ha documentado en lugares como Valencia de Alcántara, Écija, Plasencia, Jaén o Mombeltrán ${ }^{67}$. En la zona objeto de estudio también solían enriar el lino en arroyos o pozas para cocerlo. Sin ir más lejos, de nuevo los vecinos de la villa de La Rambla confirman que en el agua del concejo hacen pozas para cocer lino o pozas e represas para cocer lino. Bartolomé Ruiz Borrego, recuerda un cocedero de lino de agua del dicho arroyo, que era realengo y común y concejil (...) y Pedro Jiménez Moyano confirma que bizo ahora hace un año, algunas pozas en el dicho arroyo para enriar lino ${ }^{68}$. La actividad era tan frecuente, que incluso

65 R. CóRdoba De La Llave, "Industria y artesanía rural en la Corona de Castilla a fines de la Edad Media", Industrias y mercados rurales en los reinos hispánicos (siglos XIII-XV), SEEM, Madrid, 2017, 37-62, 60-61.

66 1519.09.03, AMCO, C-257, doc. 1, s.f.

${ }^{67}$ D. Bohórquez, Ordenanzas del concejo de Valencia de Alcántara, Cáceres, 1982, 182; M. MARTín OjedA, Ordenanzas del concejo de Écija (1465-1600), Ayto. de Écija, Écija, 1990, 193; E. C. DE SANTOS CANAlejo, La historia medieval de Plasencia y su entorno geohistórico: la Sierra de Béjar y la Sierra de Gredos, Cáceres, 1986, 415; R. CóRdoba DE LA Llave, «Industria y artesanía rural en la Corona de Castilla..., 53 y M. D. GARCía Oliva, Organización económica y social del concejo de Cáceres y su tierra en la Baja Edad Media, Institución Cultural "El Brocense", Cáceres, 1991, 172.

68 1519.09.03, AMCO, C-257, doc. 1, s.f.

«Paisajes hídricos y poblamiento en la Campiña Cordobesa a fines...» 
los ganaderos de la zona en 1499, se quejaban porque los vecinos de algunas villas enrían lino en el Salado provocando perjuicio a sus animales ${ }^{69}$. En la parte septentrional de la provincia de Córdoba, igualmente existen áreas de cultivo del lino, utilizando arroyos como el Guadarromán ${ }^{70}$. Finalmente hay que mencionar siquiera brevemente, las norias y pozos, sobre todo en las huertas y explotaciones agrícolas, para el regadío de árboles frutales de diversa tipología y de las numerosas verduras, viñas y tierras de cereal que había sembradas. En la zona algunos habitantes suelen referirse continuamente al anoria donde sacaban agua, mientras que otros, solían fabricarlas como explica Andrés García, que asegura haber obrado el anoria de madera en la dicha huerta ${ }^{71}$. Respecto a los pozos existen infinidad de referencias sobre ellos y su función, dos ejemplos rápidos son el de Torreblanca, que estaba unido a su torre homónima y solían nombrarlo como el poso de agua que en ello estát ${ }^{72}$ y el pozo de La Culebrilla, que lo crearon para buscar $\operatorname{agua}^{73}$.

En otro orden de cosas y como sucede en muchos lugares de la Corona castellana, en el ámbito rural cordobés, la principal función del agua era el consumo humano y animal. El origen de este aprovisionamiento hídrico procedía de acuíferos o mantos freáticos que eran conectados a través de pozos, aljibes, abrevaderos y fuentes ${ }^{74}$. Si se centra la atención sobre las fuentes o charcos, como eran también conocidas en época bajomedieval ${ }^{75}$,

69 1499.06.07, AMCO, LAC 7, s.f.

70 J. B. CARPIO DuEÑAS, "Evolución del paisaje y aprovechamientos económicos en la falda de la sierra cordobesa (siglos XIII-XV)", Meridies. Revista de Historia Medieval 9, 2011, 87-121, 117.

71 1493.07.05, AchGr, leg. 1432, núm. 13, fol. 136r.

72 1475.05.18, AHN, Sección Nobleza, Luque, C-796, doc. 1-3, fols. 1r-6v.

73 1492.09.30, AMCO, C-256, doc. 8, s.f.

74 Así también se documenta para la Campiña jerezana: E. MARTín GutiÉRrez, La identidad de Jerez de la Frontera..., 24-30.

75 Estas fuentes o charcos, son diferentes si se profundiza en el vocabulario de los humedales. El primer concepto se trata de un símil de manantial extendiéndose a las diversas construcciones que han ido erigiéndose por medio del hombre, mientras que el 
solían ser continuamente frecuentadas por los vecinos de los núcleos rurales para surtirse de la cantidad necesaria para el sustento humano. Resultado de ello, es la continua creación de nuevas construcciones que asegurase dicho suministro. Por ejemplo, para fines de los años sesenta del siglo XV se creó el denominado "charco de la Tabla", ubicado en el cortijo de la Vega. Según explica Alonso Sánchez, zahonero, observó cómo su padre y otros aparceros hacían:

"una estacada de palos, bardas y tierra, para que el agua lubia pudiera acogerse para el ganado, y al invierno cada año horadaban la dicha presa porque el agua lubia corriese y no se le hinchase el dicho charco e hoyo de cieno, e cada verano volviendo hacer tal dicho estanco y reparallo (...) y este testigo fizo e trabajó su parte en el fazer de las dichas estacadas del dicho charco la Tabla"76.

El uso del agua para abrevar al ganado que se cría en la comarca aparece en numerosos testimonios. Muchos abrevaderos se localizan al lado de las citadas fuentes de agua. Así desde 1465 las personas acudían a ellos, como el del llamado cortijo de Los Pinedas, donde solían comer y pacer con ganados y beber las aguas ${ }^{77}, \mathrm{y}$ en la aldea de La Membrilla, en la fuente de la Alcoba, muy frecuentada con el mismo fin e incluso permitían que los pastores puedan facer foyas para recoger el agua para que mejor se puedan abrevar los ganados mayores e menores ${ }^{78}$. De igual modo en el cortijo de Prados Rubios, los vecinos confirman que desde principios del siglo XVI usaban vnos manaderos de agua que se dice la fuente del Espino y alli iban a beber y dar agua a los ganados ${ }^{79}$, o en el citado Charco de la Tabla,

charco, es una lámina de agua de una extensión inferior a los 10 metros de diámetro y con una durabilidad bastante breve, ver F. GONZÁLEZ BERNÁLDEZ, Los paisajes del agua: terminología popular de los humedales, Madrid, 1992, 68 y 90-91.

76 1516.10.01, AMCO, C-241, doc. 47, s.f.

77 1515.03.10, AMCO, C-1027, doc. 31-2, s.f.

78 1516.09.20, AMCO, C-242, doc. 57, s.f.

79 1547.11.12, AMCO, C-171, doc. 11, fol. 2r. y 1519.s.m.s.d, AchGr, leg. 2468, núm. 8, fol. $42 \mathrm{v}$.

«Paisajes hídricos y poblamiento en la Campiña Cordobesa a fines...» 
donde se recogía alguna agua e sacábanla con una caldera y un tinajón daban de beber a las yeguas ${ }^{80}$. En términos generales, la mayoría de las fuentes de agua suelen tratarse de alcobas, que son:

"pequeñas obras de fábrica, consistentes en su mayoría de una arqueta de planta cuadrangular cubierta mediante cúpula de media naranja de ladrillo o bóveda de medio cañón donde, prácticamente al nivel de superficie, eran recogidas las aguas para ser conducidas hasta un lugar más o menos distante de su nacimiento" 81 .

A modo de ejemplo, se puede observar la ilustración 2, que es la alcoba de Poblete hoy día y que está documentada desde los siglos bajomedievales.

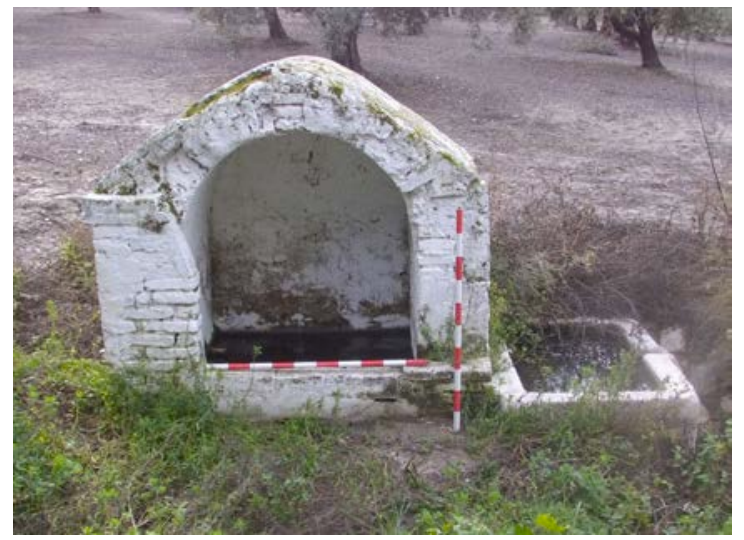

Ilustración. 2. Alcubilla de Poblete en la actualidad (J. López).

Las continuas construcciones y reparaciones de las obras hidráulicas esparcidas por todo el territorio rural cordobés, no era un casual. Desde el propio concejo de Córdoba se venía practicando esta política de mantenimiento y conservación de puentes, fuentes, gestión del agua, que suponía un desembolso

80 1516.10.01, AMCO, C-241, doc. 47, s.f.
81 R. CÓRDOBA DE LA LLAVE, "Fuentes de agua...", 175. 
económico más de las arcas ${ }^{82}$. En contrapartida, el concejo tuvo pequeños ingresos, como la renta de los aguadores o azacanes que permitía regular el transporte y repartimiento del agua, aunque repercutía poco beneficio económico en el tesoro concejil $^{83}$. El recurso hídrico era tan importante que cuando realizaban una toma de posesión, también estaba el agua muy presente. Dos casos que reflejan esto pertenecen al siglo XV. Uno procede de mayo de 1443 cuando don Alfonso Gutiérrez de los Ríos tomó posesión de su villa de Fernán Núñez, entre las acciones que realizó se destaca e tomó de las aguas con sus manos e derramó a una parte e a otra ${ }^{84}$. Asimismo para 1475 cuando adquieren la fuente de Don Tomás, el nuevo propietario don Alfon de Córdoba llegó a la dicha fuente de agua que disen de don Tomás (...) e echó piedras en la dicha fuente. Unos años después, al pasar a manos de don Pedro de Solier, se cita con la mitad de la fuente antigua y agua de ella que dicen de don Tomás (...) y, en el acto de la toma de posesión, en la fuente de don Tomás arrojaron algunas piedras ${ }^{85}$.

En último lugar, es necesario hacer hincapié brevemente sobre los comportamientos sociales acerca de la utilización del agua, es decir, cómo estos puntos de abasto se convierten en un aspecto ameno, de ocio o conflictivo y violento. Sin duda, se trata de un tema que permitiría extenderse muchísimo más en otro trabajo. En el marco rural analizado se ha identificado la presencia de actividades de juego por parte de vecinos de la zona. Por ejemplo, algunos de ellos, manifiestan que iban a beber a la

82 J. LÓPEZ Rider, "El gasto municipal de los concejos castellanos a fines de la Edad Media: el caso de Córdoba en la segunda mitad del siglo XV (1452-1500)", Historia. Instituciones. Documentos 42, 2015, 199-239, 219-222 y J. L. DEL PinO GARCíA, "El concejo de Córdoba a fines de la Edad Media: estructura interna y política municipal", Historia. Instituciones. Documentos 20, 1993, 355-402, 390.

83 Por ejemplo para 1452-1453 solamente se ingresó $1.700 \mathrm{mrs}$. para el concejo cordobés. En J. LÓPEZ RiDER, “Aportación al estudio de la hacienda del concejo de Córdoba a fines de la Edad Media”, Historia. Instituciones. Documentos 41, 2014, 275-319, 304-305.

84 1443.05.31, AHN, Sección Nobleza, Fernán Núñez, C-505, doc. 4, fol. 1 r. 85 1475.05.18, AHN, Sección Nobleza, Luque, C-796, doc. 1-3, fols. 1r-6v.

«Paisajes hídricos y poblamiento en la Campiña Cordobesa a fines...» 
cueva donde nace el agua (...) y juegan a la ballesta alli diciendo que tienen aquella posesión ${ }^{86}$. La otra realidad, son las agresiones interpersonales con motivo del derecho al disfrute del agua. Así en 1514 se produce una denuncia sobre los arrendadores del cortijo de Barrionuevo, porque estaban vendiendo el agua del pozo de Cabañas a los vecinos de La Culebrilla ${ }^{87}$. En otra ocasión, varios testigos manifiestan que dos pastores estaban peleando porque uno deseaba entrar con sus cabras a beber en la fuente del Alcoba y el otro no lo consentía. El resultado fue que terminaron a pedradas deqiendo el uno que avia de entrar a beber e el otro que no lo avia de entrar, e hasta que se dieron cada dos o tres pedradas en las costillas, pero que en fin no bebió el agua con los dichos ganados ${ }^{88}$. Y en la fuente de Fuencubierta de Guadalmazán, varios pastores deseaban usar el agua y se la defendieron con violencia extrema, le han corrido los ganados y le han atemorizado para que no entrasen a beber las aguas o pastar las hierbas (...) y vio un criado (...) encima de un caballo con una lanza, una ballesta y un puñal ${ }^{89}$.

\section{Consideraciones finales.}

En general, lo expuesto en estas líneas deja entrever que la Campiña del reino de Córdoba para finales de la Edad Media, poseía un conjunto de paisajes de agua variado y muy presente en la vida de la sociedad de aquellos momentos. Una red hidrográfica que tenía un gran protagonismo tanto para la subsistencia de los propios núcleos de población y sus habitantes, como para las diferentes actividades económicas que desempeñaban. Desde un primer momento es posible conocer las diversas formas de explotación de esos recursos hídricos, donde la variedad de esas actividades es muy clara. Gracias a toda esta información, es factible profundizar en la interacción que se origina entre sociedad y medio ambiente, y más concretamente,

\footnotetext{
86 1492.12.07, AMCO, C-258, doc. 3, s.f.

87 1514.10.13, AMCO, C-257, doc. 7, s.f.

88 1516.09.20, AMCO, C-242, doc. 57, s.f.

89 1513.09.08, AMCO, C-171, doc. 15, s.f.
} 
entre el poblamiento rural cordobés y el agua de su entorno. Y aunque parezca una obviedad, es innegable que el agua es un recurso de primera necesidad y esencial para aquellos lugares poblados, cuyos vecinos necesitan abastecerse y desarrollar sus actividades económicas como sigue sucediendo en nuestros días. A través de la documentación bajomedieval se ha podido detectar el marco hidrográfico existente, que no solamente sirve como recurso fundamental de subsistencia, sino que también articula el territorio incidiendo en que los lugares habitados se ubiquen en sus proximidades. De los cursos fluviales mencionados, el rio por excelencia, el Guadalquivir, proporcionaba numerosos recursos, desde posibilidad de pesca, instalación de ingenios hidráulicos hasta una arteria de comunicación y transporte principal. El resto de ríos menores y arroyos eran imprescindibles para el desempeño económico, manifestándose su utilidad para ganadería, regadío y producción industrial.

Por otra parte, el establecimiento de diferentes construcciones hidráulicas e industriales en relación al aprovechamiento hidráulico, conlleva a una transformación del paisaje de manera significativa. Molinos, norias, tenerías, tejares, fuentes, abrevaderos, pilares, caños, y un sinfín más de tipologías arquitectónicas, modifican y muestran la gestión integral del agua por parte del poblamiento. En ese sentido, las obras de nuevos ingenios y el mantenimiento de los ya existentes por parte de los concejos, tanto de la ciudad de Córdoba como de las villas rurales de la Campiña, hace posible percibir la valorización y sensibilidad que tuvieron del agua. Como hoy sucede, eran conscientes de la necesidad de tener a su disposición unos recursos hídricos que garanticen la supervivencia de las comunidades humanas y racionalizar la explotación de los mismos. Una cuestión que permite conectar con el presente y reflexionar sobre la insuficiencia de agua potable que se está viviendo en nuestros días y los problemas de sostenibilidad. 
En suma, con este trabajo se ha pretendido analizar la red hidrográfica y su utilidad para la sociedad rural cordobesa durante los siglos XIII-XV. Gracias a ello, se ha podido hacer un acercamiento a la interacción entre poblamiento y agua e intentar reflexionar sobre unos paisajes hídricos, que en gran medida, todavía siguen configurando el territorio de toda la Campiña junto a muchas de sus ingenios hidráulicos, perviviendo tanto unos como otros con su nomenclatura bajomedieval. 


\section{Bibliografía}

J.-L. ABBÉ, "Técnicas de drenaje y sociedad feudal: las lagunas del Languedoc", J. TORRÓ y G. ENRIC (eds.), Hidráulica agraria y sociedad feudal. Prácticas, técnicas, espacios, Universitat de Valencia, 2012, 187-206.

K. BERTHIER, "Cîteaux y el control del agua en la Edad Media: la creación del canal de cent-fonts”, J. TORRÓ y G. ENRIC (eds.), Hidránlica agraria y sociedad feudal. Prácticas, técnicas, espacios, Universitat de Valencia, 2012, 51-78.

D. BALESTRACCI, "L'uso delle acque interne nel Senese nel Medioevo", A. Malvolti y G. PINTO (a cura di), Incolti, fiumi e paludi. Utilizzazione delle risorse naturali nella Toscana medievale e moderna, Leo S. Olschki Editore, Firenze, 2003,117-141.

G. Bertrand, "Para una historia ecológica de la Francia rural. Primera parte: el imposible tableau geográfico", C. BERTRAND y G. BERTRAND, Geografía del Medio Ambiente: El Sistema GTP: Geosistema, territorio, paisaje, Granada, 2006, 161-185.

R. BODEI, Paisajes sublimes. El hombre ante la naturaleza salvaje, Madrid, 2011.

D. BOHÓRQUEZ, Ordenanzas del concejo de Valencia de Alcántara, Cáceres, 1982.

J. A. Bonachía Hernando, "El agua en las Partidas", M. I. Del VAL VAldivieso y J. A. Bonachía HeRnAndo (Coords.), Agua y sociedad en la Edad Media hispana, Granada, 2012, 13-64.

$M^{a}$ A. CARMONA RuIZ, "El aprovechamiento de los espacios incultos en la Andalucía Medieval: el caso de la Sierra Norte de Sevilla”, en E. MARTÍN GuTIÉRREZ, (coord.), El paisaje rural en Andalucia Occidental durante los siglos bajomedievales. Actas de las I Jornadas Internacionales sobre Paisajes rurales en época medieval, Cádiz, 1-2 de abril de 2009, Universidad de Cádiz, 2011, 193-208.

J. B. CARPIO DUEÑAs, "Evolución del paisaje y aprovechamientos económicos en la falda de la sierra cordobesa (siglos XIII-XV)", Meridies. Revista de Historia Medieval 9, 2011, 87-121.

Conserjería de Medio Ambiente, Plan Andaluz de Humedales, CMAJunta de Andalucía, Sevilla, 2002.

CONSERJERía De MEDiO AmBIENTE, Un día en las lagunas del Sur de Córdoba, CMA-Junta de Andalucía, Sevilla, 2006.

«Paisajes hídricos y poblamiento en la Campiña Cordobesa a fines...» 
Conserjería de Medio Ambiente, Reservas y Parajes Naturales. Zonas búmedas del Sur de Córdoba. Memoria anual de actuaciones, CMA-Junta de Andalucía, Sevilla, 2007.

R. CÓRDOBA DE LA LLAVE, "Navegación y transporte fluvial en la Península Ibérica a fines de la Edad Media", M. CRIADO DE VAL (coord.), Actas del III Congreso Internacional de Caminería Hispánica celebrado en Morelia (México) en julio de 1996, AACHE Ediciones, Madrid, 1997, 215-233.

R. Córdoba DE LA Llave, "Fuentes de agua del entorno de Castro del Río a fines de la Edad Media", IV Estudios de Frontera, Tradiciones, Leyendas en la Frontera, Jaén, 2002, 171-186.

R. CÓRDOBA DE LA LLAVE et alii, Los molinos hidráulicos del Guadalquivir en la ciudad de Córdoba: estudio bistórico y arquitectónico, Centro de Estudios Históricos de Obras Públicas y Urbanismo, Madrid, 2008.

R. CÓRDOBA DE LA Llave, "Los batanes hidráulicos de la cuenca del Guadalquivir a fines de la Edad Media. Explotación y equipamiento técnico", Anuario de Estudios Medievales 41-2, 2011, 593-622.

R. CÓRDOBA DE LA LLAVE, "Industria y artesanía rural en la Corona de Castilla a fines de la Edad Media", Industrias y mercados rurales en los reinos hispánicos (siglos XIII-XV), SEEM, Madrid, 2017, 37-62.

R. DELORT, "Les facteurs éco-biologiques de l'espace: permanences et mutations", Uomo e spazio nell'alto Medioevo. Settimane di Studio del Centro Italiano di Studi sull'alto Medioevo. 4-8 aprile 2002, Centro Italiano di Studi sull'alto Medioevo, Spoleto, 2 vols., 2003, vol. 1, 69-90.

J. DUMASY, "Bilan et tendances de la recherche en paléoclimatologie et éco-histoire pour la France méridionale, VIII ${ }^{-} \mathrm{XV}^{\mathrm{e}}$ siècle”, F. CLEMENT (Dir.), Histoire et nature. Pour une histoire écologique des sociétés méditerranéennes (Antiquité et Moyen Ages), Presses Universitaires de Rennes, 2011, 127-146.

J. M. Escobar CAmacho, Córdoba en la Baja Edad Media. Evolución urbana de la ciudad, Córdoba, 1989.

J. M. Escobar CAMACHO, "La Campiña de Córdoba en la Baja Edad Media: delimitación y organización espacial”, Ifigea IX, 1993, 57-75.

V. Fumagalli, Paesaggi della paura. Vita e natura nel Medioevo, Bologna, Il Mulino, 1994.

J. A. GARCÍA DE CORTÁzAR, "Sociedad rural y entorno físico: las modificaciones del paisaje en la Castilla medieval", F. SABATÉ I CURULL 
(coord.), Natura i desenvolupament: el medi ambient al'Edat Mitjana, Lleida, 2007, 251-274.

J. A. García DE CORTÁzAr, "Sociedad rural y medio físico en la España Medieval: Transformaciones del entorno físico en el Reino de Castilla en los siglos VIII al XV”, E. PÉREZ-EMBID WAMBA (coord.), La Andalucia medieval. Actas de las I Jornadas de Historia Rural y Medio Ambiente, 2002, 15-42.

M. D. GARCÍA OLIVA, Organización económica y social del concejo de Cáceres y su tierra en la Baja Edad Media, Institución Cultural "El Brocense", Cáceres, 1991.

F. GONZÁLEZ BERNÁLDEZ, Los paisajes del agua: terminología popular de los bumedales, Madrid, 1992.

E. HERMON (Dir.), Ver une gestion intégrée de l'eau dans l'Empire Romain. Actes du Colloque International Université Laval, Octubre de 2006, Roma, 2008.

E. Hermon (Dir.), Société et climats dans l'Empire Romain. Pour une perspective historique et systémique de la gestion des ressources en eau dans l'Empire Romain, Nápoles, 2009.

E. HERMON (Dir.), Riparia dans l'Empire Romain pour la définition du concept. Actes des Journées d'étude de Québec, 29-31 Octobre 2009, Oxford, 2010.

E. HERMON, "Espaces intégrés et définition du concept de riparia dans le monde romain", E. HERMON (Dir.), Riparia dans l'Empire Romain pour la définition du concept. Actes des Journées d'étude de Québec, 29-31 Octobre 2009, Oxford, 2010, 329-338.

E. HERMON, "Riparia dans l'Empire Romain: pour la définition d'un concept", E. HERMON (Dir.), Riparia dans l'Empire Romain pour la définition du concept. Actes des Journées d'étude de Québec, 29-31 Octobre 2009, Oxford, 2010, 3-12.

E. Hermon, "Préface", L. G. Lagostena Barrios (Ed.), Qui lacus aquae stagna paludes sunt... Estudios históricos sobre bumedales en la Bética, Cádiz, 2015, 1-6

E. HERMON, "L'évolution diachronique des concepts environnementaux des deux rives de l'Atlantique. La construction du concept de Riparia comme un patrimoine culturel", Riparia 1, 2015, 120 .

«Paisajes hídricos y poblamiento en la Campiña Cordobesa a fines...» 
P. ÍÑIGO HERNÁNDEZ, "La pesca fluvial y el consumo de pescado en Córdoba (1450-1525)", Anuario de Estudios Medievales 27-2, 1997, $1045-$ 1116.

R. IZQuiERDo BENITO, "El agua en Toledo en la Edad Media", M. I. Del Val Valdivieso y J. A. Bonachía Hernando (Coords.), Agua y sociedad en la Edad Media hispana, Granada, 2012, 211-240.

I. JALDÚN, Introducción a la historia universal (Al-Muqaddimab), México, Fondo de Cultura Económica, 1977.

J. A. LÓPEZ-GETA y J. M ${ }^{a}$ FORNÉS AZCOITI, La geología e hidrogeología en la investigación de humedales, Junta de Andalucía, Ministerio de Ciencia e Innovación e Instituto Geológico y Minero de España, Madrid, 2009.

J. LÓpez Rider, "Los molinos del río Monturque en el término municipal de Santaella (Córdoba): molino de Don Martín, un legado histórico y tecnológico", Actas del $8^{\circ}$ Congreso Internacional de Molinología: Innovación y ciencia en el Patrimonio Etnográfico, Diputación de Pontevedra, Tuy, 2012, 145-156.

J. LÓPEZ RIDER, Estudio sobre construcciones hidráulicas e industriales de Santaella (Córdoba), Diputación Provincial de Córdoba, Córdoba, 2013.

J. LÓPEZ RIDER, "Aportación al estudio de la hacienda del concejo de Córdoba a fines de la Edad Media", Historia. Instituciones. Documentos 41, 2014, 275-319.

J. LÓPEZ RIDER, "El gasto municipal de los concejos castellanos a fines de la Edad Media: el caso de Córdoba en la segunda mitad del siglo XV (1452-1500)", Historia. Instituciones. Documentos 42, 2015, 199-239.

J. LÓPEZ RIDER, "La producción de carbón en el reino de Córdoba a fines de la Edad Media: un ejemplo de aprovechamiento del monte mediterráneo", Anuario de Estudios Medievales, 46-2, 2016, 819-858.

A. MALPICA Cuello, Las últimas tierras de al-Ándalus: paisaje y poblamiento del reino nazari de Granada, Consorcio para la Conmemoración del Primer Milenio de la Fundación del Reino de Granada, Granada, 2014.

M. MARrocCHI, "L'impaludamento della val di Chiana in epoca medievale", A. MALVOLTI y G. PINTO (a cura di), Incolti, fiumi e paludi. Utilizzazione delle risorse naturali nella Toscana medievale e moderna, Leo S. Olschki Editore, Firenze, 2003, 73-93.

M. MARROCCHI, "La historiografía italiana y los paisajes rurales en Toscana en la Baja Edad Media", en E. MARTín GUTIÉRREZ, (coord.), El paisaje rural en Andalucia Occidental durante los siglos bajomedievales. Actas 
de las I Jornadas Internacionales sobre Paisajes rurales en época medieval, Cádiz, 1-2 de abril de 2009, Universidad de Cádiz, 2011, 157-172.

E. Martín GutiérRez, La identidad de Jerez de la Frontera. Territorio y Poblamiento durante la Baja Edad Media, Universidad de Cádiz, Cádiz, 2003, 24-30.

E. MArtín GutiÉrReZ, "El agua en Tempul a finales de la Edad Media”, L. G. LAGÓSTENA BARRIOS (Ed.), Lacus autem idem et stagnus, ubi inmensa aqua convenit. Estudios históricos sobre humedales en la Bética (II), Cádiz, 2016, 67-84.

E. MARTín GutiÉRrEZ, "Paisajes palustres entre la desembocadura del Guadalquivir y el Guadalete durante los siglos XIII al XV", A. MALPICA Cuello (Ed.), Zonas húmedas de la Andalucía medieval. Inicio de un debate, Granada, 2017, 17-49.

M. MARTín OJEDA, Ordenanzas del concejo de Écija (1465-1600), Ayto. de Écija, Écija, 1990.

C. MARTíN-Puertas, "Arid and Humid phases in Southern Spain during the Last 4000 Years: the Zoñar Lake Record, Cordoba", The Holocene, 18-6, 2008, 907-921.

C. MARTÍN-PUERTAS et alii, "La paleolimnología en la gestión de los humedales: la laguna de Zóñar", J. A. LÓPEZ-GETA y J. Mª FORNÉS AzCOITI, La geología e bidrogeología en la investigación de humedales, Junta de Andalucía, Ministerio de Ciencia e Innovación e Instituto Geológico y Minero de España, Madrid, 2009, 199-214.

J. NARANjo Ramírez, R. Garzón García y A. Mulero MENDIGORRI, "Los humedales del sur de Córdoba: conflictos y fricciones entre espacios protegidos y medio rural circundante", R. BAENA ESCUDERO et alii (coord.), Investigando en rural, Ulzama, Navarra, 2012, 493-502.

M. Nieto Cumplido, Corpus Mediaevale Cordubense, 2 vols., Montes de Piedad y Caja de Ahorros, Córdoba, 1979-1980.

M. PARRA VillaescusA, "Aguas peligrosas"-aguas aprovechables: concepción ideológica y realidad productiva de los marjales. El sur del reino de Valencia (XIV-XV)", Mª. I. DEL VAL VALDIVIESO (Coord.), La percepción del agua en la Edad Media, Universitat d'Alcalat, 2015, 39-84.

J. L. DEL PINO GARCÍA, "El concejo de Córdoba a fines de la Edad Media: estructura interna y política municipal", Historia. Instituciones. Documentos 20, 1993, 355-402.

«Paisajes hídricos y poblamiento en la Campiña Cordobesa a fines...» 
G. PINTO, "Incolti, fiui, paludi. Alcune considerazioni sulle risorse naturali nella Toscana medieale e Moderna", A. MALVOLTI y G. PINTO (a cura di), Incolti, fiumi e paludi. Utilizzazione delle risorse naturali nella Toscana medievale e moderna, Leo S. Olschki Editore, Firenze, 2003, 1-16.

E. Olmos Herguedas, Agua, paisaje y ecohistoria: la comarca de Cuéllar a partir del siglo XIII, Universidad de Valladolid, 2011.

A. OREJAS SACO DEL VALLE, "La gestión del agua en época romana en el ámbito rural”, G. T. SCHATTNER y F. VALDÉS FERNÁNDEZ (Coords.), El suministro de agua a Toledo y el saber bidráulico durante la Antigüedad y la Edad Media, Berlín, 2017, 175-183.

J. PASCUAL BAREA, "El paisaje histórico de los términos de Tarifa y Algeciras según la toponimia del Libro de la Montería en el siglo XIV", en E. MARTÍN GUTIÉRREZ, El paisaje rural en Andalucia Occidental durante los siglos bajomedievales: actas de las I Jornadas Internacionales sobre paisajes rurales en época medieval, Cádiz, abril de 2009, Universidad de Cádiz, 2011, $107-$ 146.

R. Pinilla Melguizo, "Saneamiento urbano y medio ambiente en la Córdoba islámica (siglos VIII-XIII)", en J. BERBEL et alii (Eds.), Las Ordenanzas de limpieza de Córdoba (1498) y su proyección, Córdoba 1999, 3954.

G. Pizarro Berenguela, El abastecimiento de agua a Córdoba: arqueología e historia, Córdoba, 2014.

E. C. DE SAntos CANAlejo, La historia medieval de Plasencia y su entorno geohistórico: la Sierra de Béjar y la Sierra de Gredos, Cáceres, 1986.

G. TRAINA, Paludi e bonifiche del mondo antico, L'Erma di bretschneider, Roma, 1988.

J. TORRÓ, "Colonización cristina y roturación de áreas palustres en el reino de Valencia. Los marjales de la villa de Morvedre (ca. 12601330)", J. TORRÓ y G. ENRIC (eds.), Hidráulica agraria y sociedad feudal. Prácticas, técnicas, espacios, Universitat de Valencia, 2012,147-186.

Ma I. DEL VAL VAlDIVIESO, Agua y poder en la Castilla bajomedieval. El papel del agua en el ejercicio del poder concejil a fines de la Edad Media, Junta de Castilla y León, Valladolid, 2003.

$\mathrm{M}^{a}$ I. DEL VAL VALDIVIESO, “¿Por qué estudiar hoy el problema del agua en la Edad Media?”, en L. ADÃO DA FOnSECA; L. C. AMARAL e $\mathrm{M}^{\mathrm{a}} \mathrm{F}$. FERREIRA SANTOS (coords.), Os reinos ibéricos na Idade Média: livro de homenagem ao Professor Doutor Humberto Carlos Baquero Moreno, Porto: FLULP, Civilização Editora, vol. 1, 2003, 1083-1089. 